\title{
Chemical fate and settling of mineral dust in surface seawater after atmospheric deposition observed from dust seeding experiments in large mesocosms
}

\author{
K. Desboeufs ${ }^{1}$, N. Leblond ${ }^{2}$, T. Wagener $^{3}$, E. Bon Nguyen ${ }^{1}$, and C. Guieu ${ }^{4,5}$ \\ ${ }^{1}$ LISA, CNRS UMR7583, Université Paris-Diderot et Université Paris-Est Créteil, 61, av du Général de Gaulles, \\ Créteil, France \\ ${ }^{2}$ Sorbonne Universités, UPMC Univ Paris 06, UMS0829, Observatoire Océanologique, Villefranche-sur-Mer, France \\ ${ }^{3}$ Université d'Aix-Marseille, CNRS/INSU, IRD, Institut Méditerranéen d'Océanologie (MIO), UM110, \\ 13288 Marseille, France \\ ${ }^{4}$ Sorbonne Universités, UPMC Univ Paris 06, UMR7093, LOV, Observatoire océanologique, 06230, \\ Villefranche/mer, France \\ ${ }^{5}$ CNRS, UMR7093, LOV, Observatoire océanologique, 06230, Villefranche/mer, France
}

Correspondence to: K. Desboeufs (desboeufs@lisa.u-pec.fr)

Received: 20 January 2014 - Published in Biogeosciences Discuss.: 28 March 2014

Revised: 27 August 2014 - Accepted: 7 September 2014 - Published: 13 October 2014

\begin{abstract}
We report here the elemental composition of sinking particles in sediment traps and in the water column following four artificial dust seeding experiments (each representing a flux of $10 \mathrm{~g} \mathrm{~m}^{-2}$ ). Dry or wet dust deposition were simulated during two large mesocosms field campaigns that took place in the coastal water of Corsica (NW Mediterranean Sea) representative of oligotrophic conditions. The dust additions were carried out with fresh or artificially aged dust (i.e., enriched in nitrate and sulfate by mimicking cloud processing) for various biogeochemical conditions, enabling us to test the effect of these parameters on the chemical composition and settling of dust after deposition. The rates and mechanisms of total mass, particulate organic carbon (POC) and chemical elements (Al, Ba, $\mathrm{Ca}, \mathrm{Co}, \mathrm{Cu}, \mathrm{Fe}, \mathrm{K}, \mathrm{Li}, \mathrm{Mg}$, $\mathrm{Mn}, \mathrm{Mo}, \mathrm{N}, \mathrm{Nd}, \mathrm{P}, \mathrm{S}, \mathrm{Sr}$ and Ti) transfer from the mesocosm surface to the sediment traps installed at the base of the mesocosms after dust deposition show that (1) $15 \%$ of the initial dust mass was dissolved in the water column in the first $24 \mathrm{~h}$ after seeding. Except for $\mathrm{Ca}, \mathrm{S}$ and $\mathrm{N}$, the elemental composition of dust particles was constant during their settling, showing the relevance of using interelemental ratios, such as $\mathrm{Ti} / \mathrm{Al}$ as proxy of lithogenic fluxes. (2) Whatever the type of seeding (using fresh dust to simulate dry deposition or artificially aged dust to simulate wet deposition), the particulate
\end{abstract}

phase both in the water column and in the sediment traps was dominated by dust particles. (3) Due to the high Ba content in dust, $\mathrm{Ba} / \mathrm{Al}$ cannot be used as productivity proxy in the case of high dust input in the sediment traps. Instead, our data suggests that the ratio $\mathrm{Co} / \mathrm{Al}$ could be a good productivity proxy in this case. (4) After 7 days, between 30 and $68 \%$ of added dust was still in suspension in the mesocosms. This difference in the dust settling was directly associated with a difference in POC export, since POC fluxes were highly correlated to dust lithogenic fluxes signifying a ballast effect of dust. The highest fraction of remaining dust in suspension in the mesocosm at the end of the experiment was found inversely correlated to $\mathrm{Chl} a$ increase. This suggests that the fertilizing effect of dust on autotrophs organisms, the ballast effect, and POC fluxes are strongly correlated. (5) Our data emphasize a typical mass ratio Lithogenic / POC fluxes around 30 which could be used as reference to estimate the POC export triggered by wet dust deposition event. 


\section{Introduction}

Dust transported in the atmosphere from the desert areas is known to be a major contributor to oceanic sedimentation in certain regions, notably in the Mediterranean (Loÿe-Pilot et al., 1986; Bergametti et al., 1989). In this region, the dust inputs are usually related to strong deposition pulses of mineral dust from the Sahara (Guerzoni et al., 1999). Thus, the fluctuations of past atmospheric dust fluxes can be used to reconstruct the atmospheric response to climate oscillations throughout the Mediterranean region (e.g., Moreno et al., 2002; Frigola et al., 2007). Moreover, atmospheric dust deposition constitutes the major source of nutrients $(\mathrm{N}, \mathrm{P}, \mathrm{Si}, \mathrm{Fe}$ and trace metals) in the Mediterranean surface water (Krom et al., 2004; Bonnet and Guieu, 2006; Pulido-Villena et al., 2010). Dust deposition can be also an efficient mechanism to remove dissolved nutrients from ocean surface waters, notably by adsorption onto sinking particles (e.g., Wagener et al., 2010). Thus, dust deposition plays an important role on biogeochemical elemental cycling by acting as both a source and a sink for dissolved nutrients in the Mediterranean surface seawater. Finally, dust can also affect the carbon export in marine environment via a ballast effect on POC export (Ternon et al., 2010), by increasing the sinking velocity of organic particles (Ploug et al., 2008). In consequence, a quantification of dust deposition is essential for assessing the past and present role of dust on the Mediterranean Sea.

Atmospheric dust inputs to the Mediterranean Sea are indirectly assessed from accumulation rates in sediments, and from sediment traps in the water column. Sediment traps in the Mediterranean are also used to quantify and characterize the atmospheric flux of elements from the surface to the deep sea (Goutx et al., 2000; Heimbürger et al., 2014). These marine-based methods are used to validate modeled atmospheric dust fluxes, assuming a conservative dust transfer through the water column. However, the atmospheric and oceanic fluxes estimated from simultaneous measurements of dust fluxes by marine sediment traps and by atmospheric deposition method are not linear (Bory et al., 2002; Neuer et al., 2004). The export of dust to the bottom of the sediment traps is linked to the ballast effect of organic matter produced by biological activity, and hence an efficient downward export of the dust particles to the sediment traps demands a biological activity (Bory et al., 2002; Fischer et al., 2009; Ternon et al., 2010). The high dust deposition triggers a large increase in particles concentrations, enabling aggregation processes and hence inducing a differential settling rate of dust (Lee et al., 2009). Moreover, dust particles can be horizontally advected or redistributed in the water column, before reaching the sediment trap. A number of physical and biological mechanism control oceanic dust fluxes that, so far, are difficult to discriminate and parameterize.

Practically, the estimation of dust export is made by the determination of lithogenic material in sediment traps or records. Generally, the lithogenic component is estimated from $\mathrm{Al}$ content in sediments. This method consists of considering that all $\mathrm{Al}$ recovered in sediment traps is associated with lithogenic material and that lithogenic material is mainly from dust. By using the average $\mathrm{Al}$ content in dust, the dust inputs corresponding to the lithogenic fraction found in the trap can be calculated (e.g., Bory et al., 2002). The interelemental ratios with $\mathrm{Al}$, like $\mathrm{Si} / \mathrm{Al}, \mathrm{Ti} / \mathrm{Al}$ or $\mathrm{Zr}$ / $\mathrm{Al}$ ratios in the Mediterranean region have been also extensively used as proxies for dust input (e.g., Moreno et al., 2002; Frigola et al., 2007). On the basis that $\mathrm{Ba} / \mathrm{Al}$ ratio in dust is known and likely constant, $\mathrm{Ba} / \mathrm{Al}$ is considered as a proxy for productivity and used to estimate POC export (Paytan and Kastner, 1996; Mahiques et al., 2009). However, this proxy implies that the major source of elemental $\mathrm{Ba}$ to sediments is marine barite, and that there is no significant contribution of $\mathrm{Ba}$ from other sources, or that components of $\mathrm{Ba}$ in excess other than barite are related to $\mathrm{C}$ export in a predictable way. In a similar manner, the ratio $\mathrm{Ba} / \mathrm{Ti}$ is also used as a proxy for productivity (Averyt and Paytan, 2004). Such approaches assume that the $\mathrm{Al}, \mathrm{Ba}, \mathrm{Ti}, \mathrm{Si}$ or $\mathrm{Zr}$ dust content is constant during the settling of dust particles. However, the composition of sinking particles could deviate from the initial ratio during sinking since more labile elements are released more quickly than refractory ones. For example, Ba in dust is known to be more soluble than $\mathrm{Al}$ (Desboeufs et al., 2001).

The project DUNE (a DUst experiment in a low Nutrient low chlorophyll Ecosystem) aimed at better understanding the effect of dust deposition on the surface waters biogeochemistry of the Mediterranean Sea (Guieu et al., 2010, 2014a). The approach applied in this project was to perform dust addition experiments onto large trace metals clean mesocosms. The original design of these mesocosms represented a unique opportunity to study the dust fate after deposition at the surface down to sediment traps. In particular, the use of mesocosms limits the problem of hydrodynamical artifact, i.e., lateral advection or losses of particles by currents, as observed for in situ sediment traps. In consequence, the DUNE experiments allowed assessing, in controlled conditions, the impact of dissolution, adsorption and chemical or biological process associated with the settling of particles in the surface water column in the case of high dust deposition events in an oligotrophic environment.

The set of DUNE experiments simulated either wet (DUNE-P), dry (DUNE-Q) or a succession of two wet deposition fluxes (DUNE-R) of $10 \mathrm{~g} \mathrm{~m}^{-2}$ of Saharan dust. Here, we present the total mass and the elemental composition (POC, Al, Ba, Ca, Co, Cu, Fe, K, Li, Mg, Mn, Mo, N, Nd, $\mathrm{P}, \mathrm{S}, \mathrm{Sr}$ and $\mathrm{Ti}$ ) of material collected in the traps and in the water column during the four dust addition experiments. The suite of elements was chosen to include nutrients (N, P, Si, Fe and trace metals: $\mathrm{Mn}, \mathrm{Cu}, \mathrm{Co}, \mathrm{Mo}$ ), elements used as proxies of marine productivity ( $\mathrm{POC}, \mathrm{Ca}, \mathrm{Ba}$ ), and elements used as proxies of dust input ( $\mathrm{Al}, \mathrm{Ca}, \mathrm{Ti}, \mathrm{Nd})$. We examine the chemical composition of the added dust during its sinking and the 
Table 1. Main operational details for seeding and sediment traps collection. The dust type is detailed in the session" 2.1 . Dust Characteristics": Dust07 and Dust09 correspond to the soil sampling made in Tunisia in March 2007 and March 2009 respectively; the evapocondensed soil is noted EC-Dust, and the fresh soil is noted NEC-Dust, and hence, e.g., EC Dust07 means evapocondensed dust collected in 2007.

\begin{tabular}{|c|c|c|c|c|c|c|c|}
\hline & \multicolumn{3}{|c|}{ Dust seeding } & \multicolumn{3}{|c|}{ Sediment traps collection } & \multirow[b]{2}{*}{$\begin{array}{l}\text { Average } \\
\text { Resolution }\end{array}$} \\
\hline & Date & $\begin{array}{l}\text { Dust } \\
\text { type }\end{array}$ & $\begin{array}{c}\text { Added } \\
\text { mass }\end{array}$ & $\begin{array}{l}\text { Deposition } \\
\text { type }\end{array}$ & $\begin{array}{c}\text { First } \\
\text { sample }\end{array}$ & $\begin{array}{c}\text { Last } \\
\text { sample }\end{array}$ & \\
\hline DUNE-P & 11-18 Jun 2008 & EC-Dust07 & $41.5 \mathrm{~g}$ & Wet & Seeding $+24 \mathrm{~h}$ & Seeding $+168 \mathrm{~h}$ & $48 \mathrm{~h}$ \\
\hline DUNE-Q & 20-27 Jun 2008 & NEC-Dust07 & $41.5 \mathrm{~g}$ & Dry & Seeding $+24 \mathrm{~h}$ & Seeding $+168 \mathrm{~h}$ & $48 \mathrm{~h}$ \\
\hline DUNE-R1 & 27 Jun-3 Jul 2010 & EC-Dust09 & $41.5 \mathrm{~g}$ & Wet & Seeding $+22 \mathrm{~h}$ & Seeding $+166 \mathrm{~h}$ & $24 \mathrm{~h}$ \\
\hline DUNE-R2 & 3-9 Jul 2010 & EC-Dust09 & $41.5 \mathrm{~g}$ & Wet & Seeding $+24 \mathrm{~h}$ & Seeding $+144 \mathrm{~h}$ & $24 \mathrm{~h}$ \\
\hline
\end{tabular}

efficiency of settling in relation with various high dust deposition modes (dry vs wet). The aim of this work is (1) to study the relevance of various proxies of terrigeneous or productivity fluxes and (2) to investigate the link between dust and POC fluxes as a function of mode of deposition.

Dust and POC fluxes during DUNE-R presented here were also discussed in a companion paper (Bressac et al., 2014) in which the deconvolution of the different processes involved in POC export was proposed. Coupling metabolic rates in the water column and export fluxes, POC flux directly linked to new production by autotrophs stimulated by the dust deposition was found to represent $50 \%$ of the flux, while the other $50 \%$ were attributed to the "lithogenic carbon pump", a process due to the aggregation between organic material and dust. Their conclusions are discussed in this paper by comparing the dust fluxes between the four DUNE experiments.

\section{Materials and methods}

\subsection{Dust seeding and sediment traps sampling}

The two series of mesocosm seeding experiments were undertaken at the beginning of summers 2008 and 2010 (Table 1). For these experiments, six (DUNE-P and Q) or seven (DUNE-R) mesocosms were deployed in the bay of Elbo $\left(\right.$ Scandola Marine preservation area $-8.554^{\circ} \mathrm{E}, 42.374^{\circ} \mathrm{N}$ ) during typical oligotrophic conditions (Guieu et al., 2010 and 2014a). Three or four mesocosms (D1, D2, D3 and Dopt hereafter referred as "Dust-Meso") were seeded with $41.5 \mathrm{~g}$ of dust - corresponding to a deposition flux of $10 \mathrm{~g} \mathrm{~m}^{-2}$ using a trace metal clean spray. The time of the dust addition was the start of the experiment $\left(t_{0}\right)$. For the experiments DUNE-P and DUNE-R, the seeding simulated a wet deposition event by spraying diluted cloud processed dust (see Sect. 2.2) in $4 \mathrm{~L}$ of ultrapure water. In the case of the experiment $\mathrm{R}$, two successive seedings in the same mesocosms were carried out at time $t_{0}$ then at 7 days, i.e., $164 \mathrm{~h}$ after the first seeding (first and second seedings, hereafter referred as Dune-R1 and DUNE-R2, respectively). For the experiment DUNE-Q, the seeding mimicked a dry deposition event by spraying fresh dust dispersed in local seawater. In each experiment, three other mesocosms $(\mathrm{C} 1, \mathrm{C} 2$ and $\mathrm{C} 3$, hereafter referred as "Control-Meso") were kept unseeded for reference. Mesocosms were covered in order to avoid possible additional inputs from natural dust events. The sediment traps screwed to the base of mesocosms at $15 \mathrm{~m}$ depth were recovered and replaced by divers every $48 \mathrm{~h}$ for DUNE-P and Q and every $24 \mathrm{~h}$ for DUNE-R.

\subsection{Dust characteristics}

The fine fraction $<20 \mu \mathrm{m}$ in diameter of a dry sieved alluvial soil sample collected in a dust source area in southern Tunisia $\left(33.452^{\circ} \mathrm{N}, 9.335^{\circ} \mathrm{E}\right)$ has been used to seed the mesocosms (Guieu et al., 2010). In order to obtain enough quantity of the same material, we used for seeding the fine fraction of soil as analog to Saharan aerosol particles (Desboeufs et al., 1999). Two campaigns of soil sampling were made in March 2007 and March 2009 corresponding to sieved soil Dust07 and Dust09, respectively. The comparison of the physico-chemical properties of both soil samples (chemical and mineralogical composition and size distribution) indicate a good consistency (e.g., for chemical composition in Table 2), both samples being characterized by a large proportion of quartz (40\%) and calcite (30\%), and different clay minerals $(25 \%)$ such as illite, kaolinite or palygorskite.

An ageing of fine fraction of soils has been made by mimicking cloud processing with the same procedure for the Dust07 and Dust09 (Guieu et al., 2010). The fine fraction of soil which underwent the protocol of cloud processing is noted EC-Dust for evapocondensed dust, and the fresh soil is noted NEC-Dust. The Table 1 presents the type of soils used for the three experiments. The effect of the simulated cloud processing on the formation of sulfate and nitrate at the surface of dust was checked by electronic microscope observations. This showed an enrichment of nitrogen and sulfur via the neoformation of evaporite mineral like gypsum (Fig. 1) consistent with the observations on the ageing of dust during atmospheric transport (e.g., Buseck and Posfai, 1999). The enrichment in sulfur and nitrogen was also observed on elemental composition of EC-Dust07 and EC-Dust09 by X-ray 
Table 2. Chemical composition of the fine fraction of soil $(<20 \mu \mathrm{m})$ used for different seedings. Data for major elements $(\%)$ are issued from Guieu et al. (2010) for NEC Dust 07 and EC dust 07.

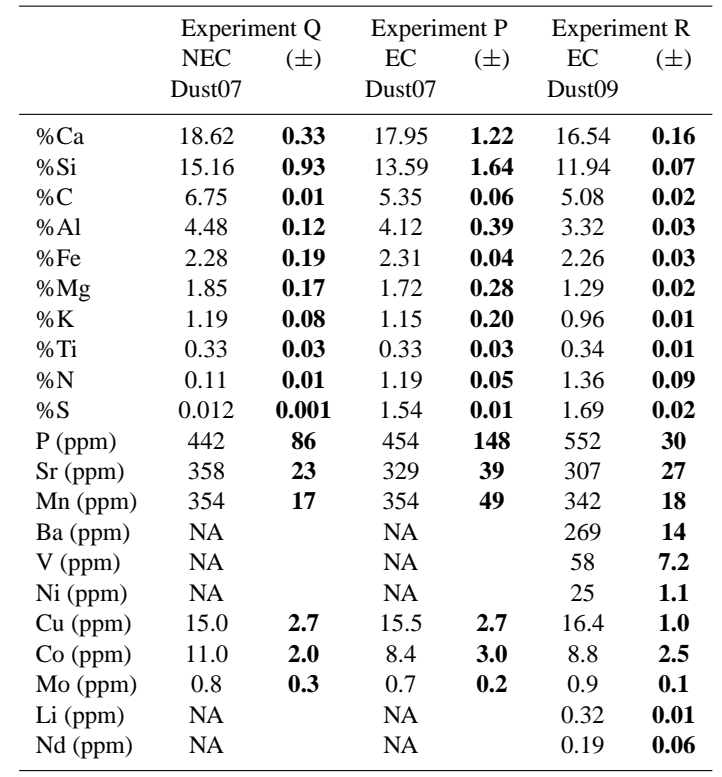

NA: not available.

spectrometry fluorescence analysis (Table 2). This enrichment is associated with a decrease in carbon content in the EC-Dust due to the reactions between calcite $\left(\mathrm{CaCO}_{3}\right)$ and inorganic acids to form the evaporite minerals, as gypsum $\left(\mathrm{CaSO}_{4}\right)$ or calcium nitrate $\left(\mathrm{Ca}\left(\mathrm{NO}_{3}\right)_{2}\right)$, which release $\mathrm{CO}_{2}$.

\subsection{Chemical characterization of sediment trap samples}

After recovery, the sample bottles of sediment traps were poisoned at $5 \%$ with a solution of buffered formaldehyde to prevent microbial degradation and grazing by swimmers and were stored at $4{ }^{\circ} \mathrm{C}$ in the dark. The samples collected in the sediment trap were treated following the standard protocol developed at the national service "Cellule Piège" of the French INSU-CNRS (http://www.obs-vlfr.fr/ LOV/Pieges). Swimmers were removed by hand-picking under a binocular microscope. The sample was rinsed three times with $50 \mathrm{~mL}$ of ultrapure (MilliQ) water in order to remove salt and was then freeze-dried. Mass fluxes were measured by weighing the freeze-dried samples. The accuracy of the weighing was $1 \%$ over the whole data series. Total concentration of carbon and nitrogen were measured in duplicate with a Perkin Elmer 2400 series II elemental analyzer (CHN) on aliquots of the desiccated samples (3-4 mg). Acid digestion described by Ternon et al. (2010) was performed on aliquots $(\sim 15 \mathrm{mg})$ of the desiccated samples. The acid digestions of the sediment trap samples were carried out in parallel with referenced material (CRM GBW07313: marine sediment from NRC) in order to check the efficiency of the acid digestion protocol. Elemental composition was mea-

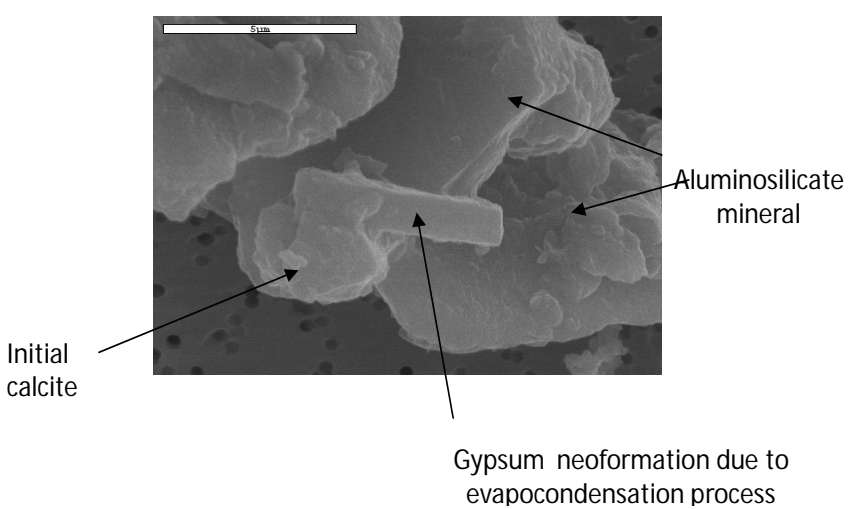

Figure 1. Electronic microscope image of neoformation of gypsum $\left(\mathrm{CaSO}_{4}\right)$ from initial calcite $\left(\mathrm{CaCO}_{3}\right)$ mixed with sulfuric acid during cloud processing simulation.

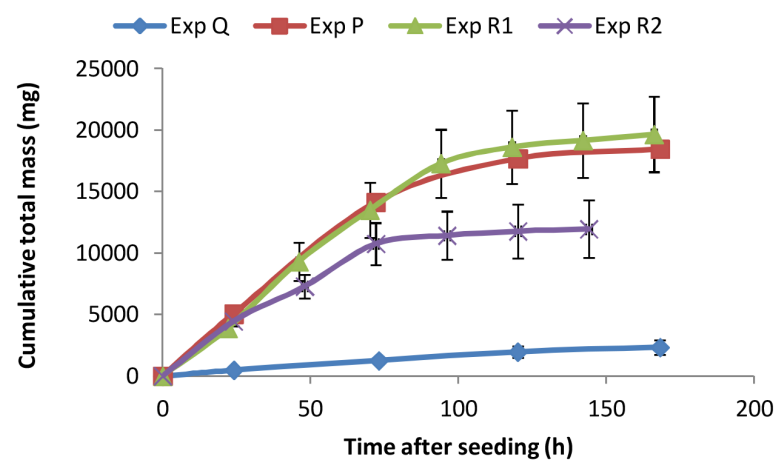

(a)

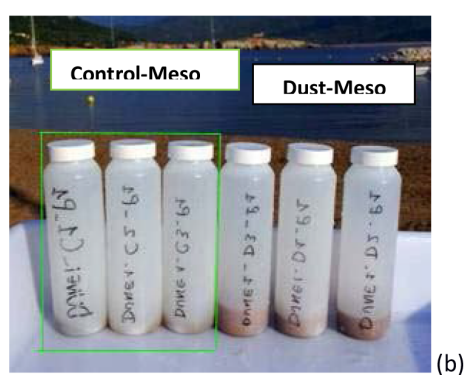

Figure 2. (a) Cumulative total mass as a function of time after seeding in the Dust-Meso sediments traps for the four experiments and (b) picture of collected mass in the sampling bottles of sediment traps for the experiment $\mathrm{P} 24 \mathrm{~h}$ after seeding.

sured on digested samples after dilution (1/100) by Ametek ICP-AES for $\mathrm{Al}, \mathrm{Ca}, \mathrm{Co}, \mathrm{Cu}, \mathrm{Fe}, \mathrm{K}, \mathrm{Li}, \mathrm{Mg}, \mathrm{Mn}, \mathrm{Mo}, \mathrm{Nd}$, $\mathrm{P}, \mathrm{S}, \mathrm{Sr}$ and Ti. The recovery for all the elements was higher than $96 \%$ in CRM samples indicating a good reliability of the digestion method. The accuracy of ICP-AES analyses was checked using SLRS-4 and SLRS-5 (River water standard materials from NRC) as CRM and the detection limits determined (Heimbürger et al., 2013). Reagent blanks were included as control for possible contamination during the analytical process. 


\subsection{Particulate concentration in the water column}

In order to follow both the settling of the added mineral particles through the mesocosms and the change of their chemical composition, particulate concentrations for $\mathrm{Al}, \mathrm{Fe}, \mathrm{Ca}$, $\mathrm{Co}, \mathrm{Cu}, \mathrm{Fe}, \mathrm{K}, \mathrm{Li}, \mathrm{Mg}, \mathrm{Mn}, \mathrm{Mo}, \mathrm{Nd}, \mathrm{P}, \mathrm{S}, \mathrm{Sr}$ and Ti were measured in the water column during DUNE-R and only for $\mathrm{Al}$ and Fe during DUNE-P and DUNE-Q. The vertical profiles of particulate $\mathrm{Al}$ and $\mathrm{Fe}$ for the experiment $\mathrm{P}$ are already described in Wagener et al. (2010). The protocol used for sampling and treatment of DUNE-P is described in Wagener et al. (2010). In brief, particulate samples were collected on cellulose acetate filters by filtering one litre of seawater. For DUNE-P and DUNE-Q, the samples were collected from 0, 5 and $10 \mathrm{~m}$ depths at $6,24,46$ and $70 \mathrm{~h}$ after seeding. For DUNE-R, the samplings were collected from six depths in the mesocosms $(0,2.5,5,7.5,10$ and $12.5 \mathrm{~m})$ up to $164 \mathrm{~h}$ after seeding. After filtration, filters were dried under a laminar flow bench and kept at room temperature until analysis. One half of the collected filters were $\mathrm{HNO}_{3} / \mathrm{HF}$ aciddigested then diluted in $10 \mathrm{~mL}$ of $0.1 \mathrm{M} \mathrm{HNO}_{3}$ after complete evaporation. The obtained solutions were analyzed at LOV (Villefranche sur mer) for $\mathrm{Al}$ and $\mathrm{Fe}$ with a Jobin Yvon (JY 138 "Ultrace") ICP-AES for DUNE-P and DUNE-Q (see Wagener et al., 2010). For DUNE-R, the digestion solutions were analysed at LISA (Créteil) by Ametek ICP-AES with the protocol used for the chemical characterization of sediments. The blank level was under the detection limits for the majority of elements except for $\mathrm{Al}, \mathrm{Fe}, \mathrm{P}$ and Ti with typical blank levels around $1 \mu \mathrm{g} \mathrm{L}{ }^{-1}$ for $\mathrm{Al}$ and $\mathrm{Fe}$ and $500 \mathrm{ng} \mathrm{L}^{-1}$ for $\mathrm{P}$ and $\mathrm{Ti}$. For $\mathrm{Co}, \mathrm{Cu}, \mathrm{Li}, \mathrm{Mo}$ and $\mathrm{Nd}$, the measured concentrations were mainly under the detection limits of this method (around $100 \mathrm{ng} \mathrm{L}^{-1}$ ). As the filters were not rinsed to remove salts, the data on $\mathrm{Ca}, \mathrm{K}, \mathrm{Mg}, \mathrm{S}$ and $\mathrm{Sr}$ were highly affected by salts contained in the seawater and are not discussed here.

\section{Results}

\subsection{Total and elemental mass in sediment traps}

The average total and elemental mass in the sediment traps for the four seeding experiments are presented in Table 3 for $\mathrm{C}, \mathrm{N}, \mathrm{Al}, \mathrm{Ca}, \mathrm{S}$ for the Control-Meso and Dust-Meso and in the supplementary section for $\mathrm{Ba}, \mathrm{Co}, \mathrm{Cu}, \mathrm{Fe}, \mathrm{K}, \mathrm{Li}, \mathrm{Mg}, \mathrm{Mn}$, Mo, Nd, P, Sr and Ti. The total and elemental masses were always higher in the Dust-Meso than in the Control-Meso, except for $\mathrm{N}$ in DUNE-Q.

For all experiments in the Dust-Meso sediment traps, the cumulative mass increase was linear with time and significant in the first $90 \mathrm{~h}$, then the cumulative mass is constant until the end of the experiments (Fig. 2a). The maximum mass collected was reached between $24 \mathrm{~h}$ and $72 \mathrm{~h}$ for the experiment $\mathrm{P}$ and $\mathrm{R} 1$, whereas for the experiment $\mathrm{R} 2$ this maximum was obtained for the first trap samples, i.e., in the first $24 \mathrm{~h}$ (Table 3). The cumulative mass at the end of experiment $\mathrm{Q}$ was 1 order of magnitude lower compared to the other experiments. In terms of chemical composition, $\mathrm{C}$ was the preponderant element in the sediment traps of ControlMeso, whereas $\mathrm{Ca}, \mathrm{C}$ then $\mathrm{Al}$ were predominant in the DustMeso sediment traps. The dominance of dust in the sediment traps for Dust-Meso was supported by the visible presence of dust in the samples after collection (Fig. 2b). The highest elemental concentrations for $\mathrm{C}, \mathrm{N}, \mathrm{Al}, \mathrm{Ca}$ and $\mathrm{S}$ were observed for the experiments DUNE-P and DUNE-R1 and the lowest for DUNE-Q, according to the variability of the cumulative mass (Table 3).

For most elements, it appears that the elemental mass concentrations were linearly correlated with the total mass with a correlation coefficient higher than 0.98 , except for $\mathrm{N}$ which presented a much larger dispersion ( $\mathrm{Al}$ and $\mathrm{N}$ are shown in Fig. 3). The linearity of the relationship implies that the sediment composition was quasi-constant from $24 \mathrm{~h}$ after seeding up to the end of the experiment (168 or $172 \mathrm{~h}$ after seeding), showing that the chemical composition of sinking particles collected in sediment traps did not evolve after the first $24 \mathrm{~h}$ after dust seeding. Linear regression between total mass and elemental mass enables one to estimate the $\%$ of a given element in the collected sediments. For instance, $\mathrm{Al}$ was $4.82 \pm 0.12 \%$ of the total mass during DUNE-P (Fig. 3), a value significantly higher than the initial $\mathrm{Al}$ contribution to total mass in the seeded dust $(4.12 \pm 0.39 \%$, Table 1$)$. Such higher elemental concentration in the sediment traps compared to initial concentration in the dust proxy was also observed for all the other studied elements except $\mathrm{Ca}, \mathrm{S}$ and $\mathrm{N}$. For these three elements, the mass fractions were significantly lower in the sediment traps than in the added dust.

In order to compare the composition of added mineral dust with the particles collected in the sediment traps, we normalized the elemental $(\mathrm{X})$ concentration ratio of $\mathrm{X} / \mathrm{Al}$ in sediment traps to the $\mathrm{X} / \mathrm{Al}$ ratio in dust (Table 4). We used $\mathrm{Al}$ since dissolved $\mathrm{Al}$ measurements in the water column during DUNE-R were shown to be negligible with fractional solubility ranging from 0.74 to $0.84 \%$ (Wuttig et al., 2013). Doing this, we identified enrichment or depletion of elements $\mathrm{X}$ independently of total mass variations. No significant change of $\mathrm{Ba}, \mathrm{Fe}, \mathrm{Ti}, \mathrm{Nd}, \mathrm{Mo}$ and $\mathrm{Li}$ contents was observed between added dust and collected particles in the Dust-Meso sediment traps. In contrast, for $\mathrm{C}, \mathrm{Co}, \mathrm{Cu}$ and $\mathrm{K}$, a systematic enrichment in all experiments was found. Inversely, an important depletion of $\mathrm{Ca}$ and $\mathrm{S}$ was observed. The behavior of $\mathrm{N}$ and $\mathrm{P}$ was contrasted depending on the experiments: during DUNE-Q, $\mathrm{N}$ and $\mathrm{P}$ were highly enriched in the sediment traps compared to the added dust; $\mathrm{N}$ was depleted in the sediment traps compared to the added dust during DUNE-P and DUNE-R; no significant enrichment or depletion in $\mathrm{P}$ was observed during DUNE-P and DUNE-R.

Regarding the depletion of $\mathrm{Ca}, \mathrm{N}, \mathrm{S}$, they are the major constituents of evaporite minerals as gypsum $\left(\mathrm{CaSO}_{4}\right)$ or cal- 
Table 3. Total and elemental masses (mg) in the sediment traps of Control-Meso (samples xxC) and Dust-Meso (samples xxD) for the 4 seeding experiments: Q, P, R1 and R2.

\begin{tabular}{|c|c|c|c|c|c|c|c|}
\hline Samples ID & Sampling time (h) & Total mass & $\mathrm{C}$ & $\mathrm{N}$ & $\mathrm{Al}$ & $\mathrm{Ca}$ & $S$ \\
\hline \multicolumn{8}{|c|}{ Experiment $\mathrm{P}$} \\
\hline $\mathrm{P} 1 \mathrm{C}$ & 24 & $132 \pm 86$ & $30.0 \pm 18.8$ & $3.7 \pm 2.2$ & $3.1 \pm 2.2$ & $5.2 \pm 3.2$ & $1.0 \pm 0.7$ \\
\hline $\mathrm{P} 2 \mathrm{C}$ & 72 & $272 \pm 191$ & $59.1 \pm 41.9$ & $6.9 \pm 5.5$ & $9.0 \pm 6.3$ & $11.1 \pm 7.2$ & $1.0 \pm 0.7$ \\
\hline P3C & 120 & $140 \pm 122$ & $33.7 \pm 25.7$ & $3.2 \pm 2.8$ & $2.4 \pm 3.4$ & $5.1 \pm 6.0$ & $0.8 \pm 1.0$ \\
\hline $\mathrm{P} 4 \mathrm{C}$ & 168 & $225 \pm 210$ & $17.2 \pm 16.5$ & $1.6 \pm 1.5$ & $1.2 \pm 1.1$ & $2.7 \pm 2.5$ & $0.5 \pm 0.4$ \\
\hline \multicolumn{2}{|c|}{ Cumulated mass } & $769 \pm 327$ & $140.0 \pm 12.8$ & $15.4 \pm 2.8$ & $15.7 \pm 3.2$ & $24.1 \pm 1.2$ & $3.2 \pm 0.5$ \\
\hline P1D & 24 & $5051 \pm 1458$ & $350 \pm 93$ & $12.6 \pm 1.2$ & $234 \pm 78$ & $747 \pm 260$ & $29.4 \pm 1.2$ \\
\hline $\mathrm{P} 2 \mathrm{D}$ & 72 & $9092 \pm 3008$ & $633 \pm 219$ & $22.1 \pm 7.2$ & $443 \pm 145$ & $1340 \pm 432$ & $31.1 \pm 12.2$ \\
\hline P3D & 120 & $3544 \pm 1755$ & $281 \pm 153$ & $11.9 \pm 6.4$ & $168 \pm 86$ & $499 \pm 254$ & $12.7 \pm 7.2$ \\
\hline P4D & 168 & $788 \pm 229$ & $107 \pm 22$ & $8.8 \pm 1.0$ & $34 \pm 11$ & $93 \pm 26$ & $4.2 \pm 1.2$ \\
\hline \multicolumn{2}{|c|}{ Cumulated mass } & $18475 \pm 1690$ & $1372 \pm 149$ & $55.4 \pm 6.9$ & $881 \pm 78$ & $2679 \pm 220$ & $77.4 \pm 13.4$ \\
\hline \multicolumn{8}{|c|}{ Experiment $\mathrm{Q}$} \\
\hline Q1C & 24 & $98 \pm 54$ & $22.9 \pm 9.4$ & $3.3 \pm 1.0$ & $2.2 \pm 1.6$ & $5.5 \pm 3.5$ & $0.6 \pm 0.3$ \\
\hline $\mathrm{Q} 2 \mathrm{C}$ & 73 & $92 \pm 51$ & $19.0 \pm 10.8$ & $2.3 \pm 1.2$ & $1.7 \pm 1.4$ & $4.1 \pm 2.8$ & $0.4 \pm 0.3$ \\
\hline Q3C & 120 & $112 \pm 15$ & $24.2 \pm 4.6$ & $3.0 \pm 0.7$ & $2.5 \pm 0.5$ & $5.6 \pm 0.6$ & $0.7 \pm 0.2$ \\
\hline $\mathrm{Q} 4 \mathrm{C}$ & 168 & $146 \pm 84$ & $31.8 \pm 18.7$ & $3.7 \pm 2.2$ & $3.9 \pm 2.8$ & $6.9 \pm 4.4$ & $1.1 \pm 0.7$ \\
\hline \multicolumn{2}{|c|}{ Cumulated mass } & $448 \pm 165$ & $97.9 \pm 35.0$ & $12.3 \pm 4.0$ & $10.4 \pm 5.7$ & $22.1 \pm 8.6$ & $2.8 \pm 1.3$ \\
\hline Q1D & 24 & $480 \pm 198$ & $53.0 \pm 19.0$ & $5.3 \pm 2.3$ & $22.2 \pm 14.3$ & $54.4 \pm 33.6$ & $2.4 \pm 1.2$ \\
\hline Q2D & 73 & $781 \pm 28$ & $69.0 \pm 3.2$ & $4.4 \pm 0.4$ & $30.4 \pm 8.8$ & $73.8 \pm 20.2$ & $2.1 \pm 0.6$ \\
\hline Q3D & 120 & $703 \pm 260$ & $66.7 \pm 23.2$ & $4.7 \pm 1.5$ & $24.7 \pm 9.5$ & $59.6 \pm 21.9$ & $1.8 \pm 0.6$ \\
\hline Q4D & 168 & $368 \pm 118$ & $36.1 \pm 11.2$ & $2.8 \pm 0.7$ & $13.2 \pm 4.4$ & $31.1 \pm 10.4$ & $1.1 \pm 0.4$ \\
\hline \multicolumn{2}{|c|}{ Cumulated mass } & $2332 \pm 419$ & $224.8 \pm 38.3$ & $17.2 \pm 3.8$ & $90.5 \pm 30.4$ & $218.8 \pm 70.1$ & $7.4 \pm 2.2$ \\
\hline \multicolumn{8}{|c|}{ Experiment R1 } \\
\hline $\mathrm{R} 3 \mathrm{C}$ & 22 & $276 \pm 14$ & $45.6 \pm 3.6$ & $3.7 \pm 0.6$ & $6.8 \pm 1.3$ & $16.7 \pm 1.6$ & $1.8 \pm 0.5$ \\
\hline $\mathrm{R} 4 \mathrm{C}$ & 46 & $285 \pm 115$ & $55.7 \pm 23.8$ & $5.6 \pm 2.5$ & $7.1 \pm 3.7$ & $12.2 \pm 5.6$ & $1.7 \pm 1.0$ \\
\hline $\mathrm{R} 5 \mathrm{C}$ & 70 & $173 \pm 43$ & $34.5 \pm 7.5$ & $3.6 \pm 0.7$ & $3.9 \pm 0.9$ & $5.3 \pm 0.6$ & $1.1 \pm 0.3$ \\
\hline $\mathrm{R} 6 \mathrm{C}$ & 94 & $168 \pm 75$ & $35.8 \pm 15.7$ & $4.0 \pm 1.9$ & $3.4 \pm 1.2$ & $4.1 \pm 1.3$ & $1.0 \pm 0.4$ \\
\hline $\mathrm{R} 7 \mathrm{C}$ & 118 & $89 \pm 19$ & $18.1 \pm 4.0$ & $2.1 \pm 0.6$ & $1.3 \pm 0.2$ & $2.5 \pm 0.3$ & $0.5 \pm 0.1$ \\
\hline $\mathrm{R} 8 \mathrm{C}$ & 142 & $38 \pm 15$ & $7.1 \pm 3.4$ & $0.8 \pm 0.4$ & $0.2 \pm 0.1$ & $0.4 \pm 0.1$ & $0.1 \pm 0.0$ \\
\hline $\mathrm{R} 9 \mathrm{C}$ & 166 & $68 \pm 21$ & $14.1 \pm 3.5$ & $1.7 \pm 0.4$ & $1.9 \pm 0.7$ & $5.4 \pm 3.0$ & $0.6 \pm 0.3$ \\
\hline \multicolumn{2}{|c|}{ Cumulated mass } & $1096 \pm 111$ & $210.9 \pm 22.6$ & $21.5 \pm 2.7$ & $24.6 \pm 1.5$ & $46.7 \pm 2.8$ & $6.9 \pm 0.6$ \\
\hline R3D & 22 & $3890 \pm 599$ & $305 \pm 37$ & $12.8 \pm 2.2$ & $137 \pm 29$ & $496 \pm 77$ & $7.9 \pm 1.9$ \\
\hline R4D & 46 & $5424 \pm 956$ & $385 \pm 62$ & $14.6 \pm 3.3$ & $199 \pm 40$ & $651 \pm 98$ & $10.1 \pm 2.2$ \\
\hline R5D & 70 & $4193 \pm 1012$ & $314 \pm 87$ & $14.0 \pm 4.6$ & $182 \pm 51$ & $455 \pm 106$ & $10.0 \pm 2.6$ \\
\hline R6D & 94 & $3784 \pm 483$ & $302 \pm 39$ & $16.9 \pm 3.8$ & $165 \pm 21$ & $557 \pm 177$ & $10.1 \pm 1.9$ \\
\hline R7D & 118 & $1345 \pm 513$ & $112 \pm 40$ & $6.9 \pm 1.7$ & $59 \pm 20$ & $253 \pm 201$ & $4.2 \pm 1.8$ \\
\hline R8D & 142 & $533 \pm 98$ & $47 \pm 9$ & $3.1 \pm 0.8$ & $19 \pm 7$ & $111 \pm 97$ & $1.4 \pm 0.7$ \\
\hline R9D & 166 & $500 \pm 228$ & $51 \pm 22$ & $4.2 \pm 1.6$ & $19 \pm 8$ & $49 \pm 8$ & $1.6 \pm 0.6$ \\
\hline \multicolumn{2}{|c|}{ Cumulated mass } & $19669 \pm 2757$ & $1515 \pm 229$ & $72.6 \pm 14.8$ & $781 \pm 118$ & $2573 \pm 628$ & $45.3 \pm 8.7$ \\
\hline \multicolumn{8}{|c|}{ Experiment R2 } \\
\hline $\mathrm{R} 11 \mathrm{C}$ & 24 & $76 \pm 11$ & $16.9 \pm 2.2$ & $2.1 \pm 0.2$ & $2.4 \pm 0.3$ & $5.9 \pm 1.6$ & $0.7 \pm 0.1$ \\
\hline $\mathrm{R} 12 \mathrm{C}$ & 48 & $50 \pm 15$ & $11.2 \pm 2.7$ & $1.4 \pm 0.3$ & $1.0 \pm 0.5$ & $4.2 \pm 3.8$ & $0.4 \pm 0.3$ \\
\hline $\mathrm{R} 13 \mathrm{C}$ & 72 & $58 \pm 7$ & $12.2 \pm 3.2$ & $1.4 \pm 0.3$ & $1.2 \pm 0.0$ & $7.7 \pm 2.5$ & $0.4 \pm 0.1$ \\
\hline $\mathrm{R} 14 \mathrm{C}$ & 96 & $23 \pm 23$ & $4.0 \pm 4.0$ & $0.6 \pm 0.6$ & $0.3 \pm 0.3$ & $3.0 \pm 3.0$ & $0.3 \pm 0.3$ \\
\hline $\mathrm{R} 15 \mathrm{C}$ & 120 & $19 \pm 19$ & $3.4 \pm 3.4$ & $0.4 \pm 0.4$ & $0.3 \pm 0.3$ & $1.8 \pm 1.8$ & $0.2 \pm 0.2$ \\
\hline $\mathrm{R} 16 \mathrm{C}$ & 144 & $19 \pm 19$ & $4.0 \pm 4.0$ & $0.6 \pm 0.6$ & $0.2 \pm 0.2$ & $1.9 \pm 1.9$ & $0.2 \pm 0.2$ \\
\hline \multicolumn{2}{|c|}{ Cumulated mass (mg) } & $245 \pm 24$ & $51.8 \pm 5.6$ & $6.3 \pm 0.6$ & $5.3 \pm 0.8$ & $24.6 \pm 2.4$ & $2.2 \pm 0.2$ \\
\hline R11D & 24 & $4461 \pm 517$ & $323 \pm 31$ & $14.9 \pm 2.6$ & $161 \pm 54$ & $566 \pm 148$ & $8.6 \pm 3.1$ \\
\hline R12D & 48 & $2836 \pm 520$ & $200 \pm 42$ & $12.3 \pm 2.8$ & $119 \pm 21$ & $386 \pm 70$ & $6.2 \pm 1.2$ \\
\hline R13D & 72 & $3456 \pm 1348$ & $249 \pm 97$ & $12.6 \pm 3.5$ & $145 \pm 67$ & $496 \pm 230$ & $8.4 \pm 3.0$ \\
\hline R14D & 96 & $677 \pm 254$ & $54 \pm 18$ & $3.0 \pm 0.9$ & $24 \pm 11$ & $87 \pm 38$ & $1.3 \pm 0.6$ \\
\hline $\mathrm{R} 15 \mathrm{D}$ & 120 & $352 \pm 233$ & $31 \pm 22$ & $2.1 \pm 1.7$ & $13 \pm 9$ & $48 \pm 31$ & $1.1 \pm 0.8$ \\
\hline $\mathrm{R} 16 \mathrm{D}$ & 144 & $181 \pm 120$ & $19 \pm 12$ & $1.8 \pm 1.1$ & $6 \pm 4$ & $24 \pm 16$ & $0.7 \pm 0.4$ \\
\hline \multicolumn{2}{|c|}{ Cumulated mass (mg) } & $11962 \pm 2117$ & $876 \pm 151$ & $46.7 \pm 7.2$ & $467 \pm 98$ & $1608 \pm 260$ & $26.4 \pm 3.9$ \\
\hline
\end{tabular}


Table 4. Element $(\mathrm{X})$ enrichment factors relative to $\mathrm{Al}$, i.e., $(\mathrm{X} / \mathrm{Al})_{\text {sediment }} /(\mathrm{X} / \mathrm{Al})_{\mathrm{dust}}$ in the material collected in the sediment traps of the Dust-Meso for the four DUNE experiments.

\begin{tabular}{cccccccccccccccc}
\hline Exp. & $\mathrm{C}$ & $\mathrm{N}$ & $\mathrm{Ba}$ & $\mathrm{Ca}$ & $\mathrm{Co}$ & $\mathrm{Cu}$ & $\mathrm{Fe}$ & $\mathrm{Li}$ & $\mathrm{Mn}$ & $\mathrm{Mo}$ & $\mathrm{Nd}$ & $\mathrm{P}$ & $\mathrm{S}$ & $\mathrm{Sr}$ & $\mathrm{Ti}$ \\
\hline $\mathrm{P}$ & 1.14 & 0.19 & & 0.70 & 1.67 & 1.32 & 0.99 & & 0.72 & & & 1.09 & 0.22 & 0.76 & 0.96 \\
$\mathrm{Q}$ & 1.62 & 7.32 & & 0.58 & 1.18 & 1.26 & 0.99 & & 0.75 & & & 2.91 & & 0.88 & 1.01 \\
$\mathrm{R} 1$ & 1.24 & 0.22 & 0.93 & 0.63 & 1.95 & 2.21 & 1.04 & 1.08 & 0.94 & 1.08 & 0.96 & 1.27 & 0.11 & 1.03 & 1.02 \\
$\mathrm{R} 2$ & 1.19 & 0.24 & 1.02 & 0.69 & 1.92 & 1.18 & 1.08 & 1.13 & 0.94 & 0.86 & 0.97 & 1.23 & 0.11 & 1.01 & 1.09 \\
\hline
\end{tabular}
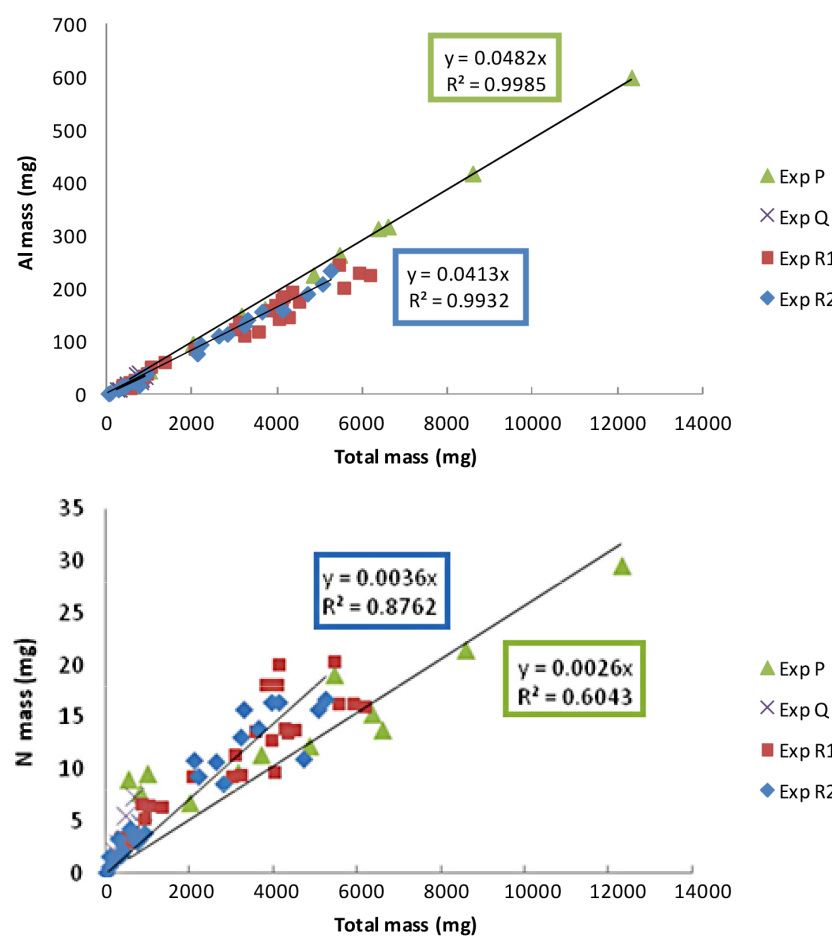

Figure 3. $\mathrm{Al}$ and $\mathrm{N}$ mass vs total mass in each sediment trap of all the samples of the Dust-Meso for the four experiments and linear regression for experiments $\mathrm{P}$ and $\mathrm{R} 2$.

cium nitrate $\left(\mathrm{Ca}\left(\mathrm{NO}_{3}\right)_{2}\right)$, which have been formed by cloud processing into EC-Dust. These minerals are known to be water soluble (Sullivan et al., 2007). Moreover, dissolution experiments performed in laboratory on EC-Dust07 showed that $100 \%$ of $\mathrm{N}$, associated with the neoformation of calcium nitrate was dissolved as nitrate in seawater (Ridame et al., 2013). Therefore, the depletion of $\mathrm{Ca}, \mathrm{S}$ and $\mathrm{N}$ was due to the dissolution of sulfate and nitrate containing particles into seawater after seeding. The depletion was observed for all the samples, whatever the time, after seeding (not shown), showing that this dissolution took place during the first $24 \mathrm{~h}$.

\subsection{Time series of elemental particulate concentrations in the water column}

The profiles of particulate aluminum (pAl) in the water column are presented for DUNE-P, -Q, -R1 and -R2 in Fig. 4. Analogous profiles for $\mathrm{Ba}, \mathrm{Fe}, \mathrm{Mn}, \mathrm{P}$, and $\mathrm{Ti}$ are given in supplementary information. The particulate concentrations in Control-Meso were always lower than the ones found in Dust-Meso at the same depth. It is obvious by comparing profiles in Dust-Meso and Control-Meso that lithogenic particles correspond mainly to added dust: particulate $\mathrm{Al}$ was thus used as a tracer of this dust. The highest pAl concentrations were observed in the first $5 \mathrm{~m}$ of mesocosms in the first $24 \mathrm{~h}$ for all the experiments (Fig. 4). For DUNE-R, higher $\mathrm{pAl}$ concentrations were found below $10 \mathrm{~m}$ after $48 \mathrm{~h}$. A large part of pAl stock in DUNE-R2 remained at the surface until $72 \mathrm{~h}$, whereas this stock was homogeneously distributed over the whole mesocosm during DUNE-R1. This is consistent with the difference of masses collected in sediment traps between DUNE-R1 and DUNE-R2; $164 \mathrm{~h}$ after the seeding, $\mathrm{pAl}$ concentrations were always higher in Dust-Meso compared to Control-Meso (not shown). No measurement of $\mathrm{pAl}$ was made at $-2.5,-47.5$ and $-10 \mathrm{~m}$ for DUNE-P and DUNE-Q, limiting the conclusions on the location of added dust for those experiments. The particulate concentrations of $\mathrm{Ba}, \mathrm{Fe}, \mathrm{Mn}, \mathrm{P}$ and Ti followed the patterns of $\mathrm{Al}$ probably indicating their lithogenic origin.

\subsection{Mass budget in the sediment traps}

A mass budget of dust integrated from the surface to the sediment traps was calculated from the mass budget in the sediment traps and pAl concentrations in the water column.

In order to estimate the fraction of dust in the total mass in the sediment traps, the dust mass which is lost from the dissolution of evaporite minerals needs to be quantified. First, we used the $\mathrm{Al}$ content in the initially added dust to estimate a theoretical dust mass in the sediment traps (Table 5) which corresponds to the total dust mass without dissolution. This estimated mass corresponds with the total dust mass without dissolution process. Then, for DUNE-P and DUNE-R, we assessed the mass of seeded dust lost after dissolution of $\mathrm{CaSO}_{4}$ and $\mathrm{Ca}\left(\mathrm{NO}_{3}\right)_{2}$ from the depleted part of $\mathrm{Ca}, \mathrm{N}$ and $\mathrm{S}$ in the sediment traps (Table 5). For DUNE-Q, we considered only a potential dissolution of $\mathrm{CaCO}_{3}$, the major material 
Table 5. Mass budget in sediment traps after the last sampling, i.e., 168h, 168h, 166h and 144h for DUNE-P, -Q, -R1 and -R2, respectively. The estimated dissolved mass of dust corresponds to the dissolved mass of $\mathrm{CaCO}_{3}$ for the $\mathrm{Q}$ experiment and of $\mathrm{CaSO} \mathrm{O}_{4}$ and $\mathrm{Ca}\left(\mathrm{NO}_{3}\right)_{2}$ for $\mathrm{P}$, $\mathrm{R} 1$ and R2 experiments, estimated from the S, N and Ca contents measured in sediment traps.

\begin{tabular}{|c|c|c|c|c|c|c|}
\hline \multirow[b]{2}{*}{ Experiments } & \multicolumn{2}{|c|}{ Total mass (mg) } & \multirow[b]{2}{*}{$\begin{array}{r}\text { Estimated } \\
\text { dissolved } \\
\text { mass of } \\
\text { dust (mg) }\end{array}$} & \multirow[b]{2}{*}{$\begin{array}{r}\% \\
\text { dissolved } \\
\text { mass }\end{array}$} & \multirow[b]{2}{*}{$\begin{array}{r}\text { Estimated } \\
\text { mass from } \\
\text { Al minus } \\
\text { dissolved } \\
\text { mass (mg) }\end{array}$} & \multirow[b]{2}{*}{$\begin{array}{r}\% \text { of dust } \\
\text { in total } \\
\text { mass }\end{array}$} \\
\hline & Measured $( \pm)$ & $\begin{array}{r}\text { Estimated } \\
\text { from } \mathrm{Al}\end{array}$ & & & & \\
\hline $\mathrm{P}$ & $18474 \pm 1690$ & 21373 & 4209 & $20 \%$ & 17165 & $93 \%$ \\
\hline Q & $2332 \pm 419$ & 2019 & 392 & $19 \%$ & 1627 & $70 \%$ \\
\hline $\mathrm{R} 1$ & $19669 \pm 2757$ & 23557 & 4816 & $20 \%$ & 18741 & $95 \%$ \\
\hline $\mathrm{R} 2$ & $11962 \pm 2123$ & 14067 & 2616 & $19 \%$ & 11451 & $96 \%$ \\
\hline
\end{tabular}

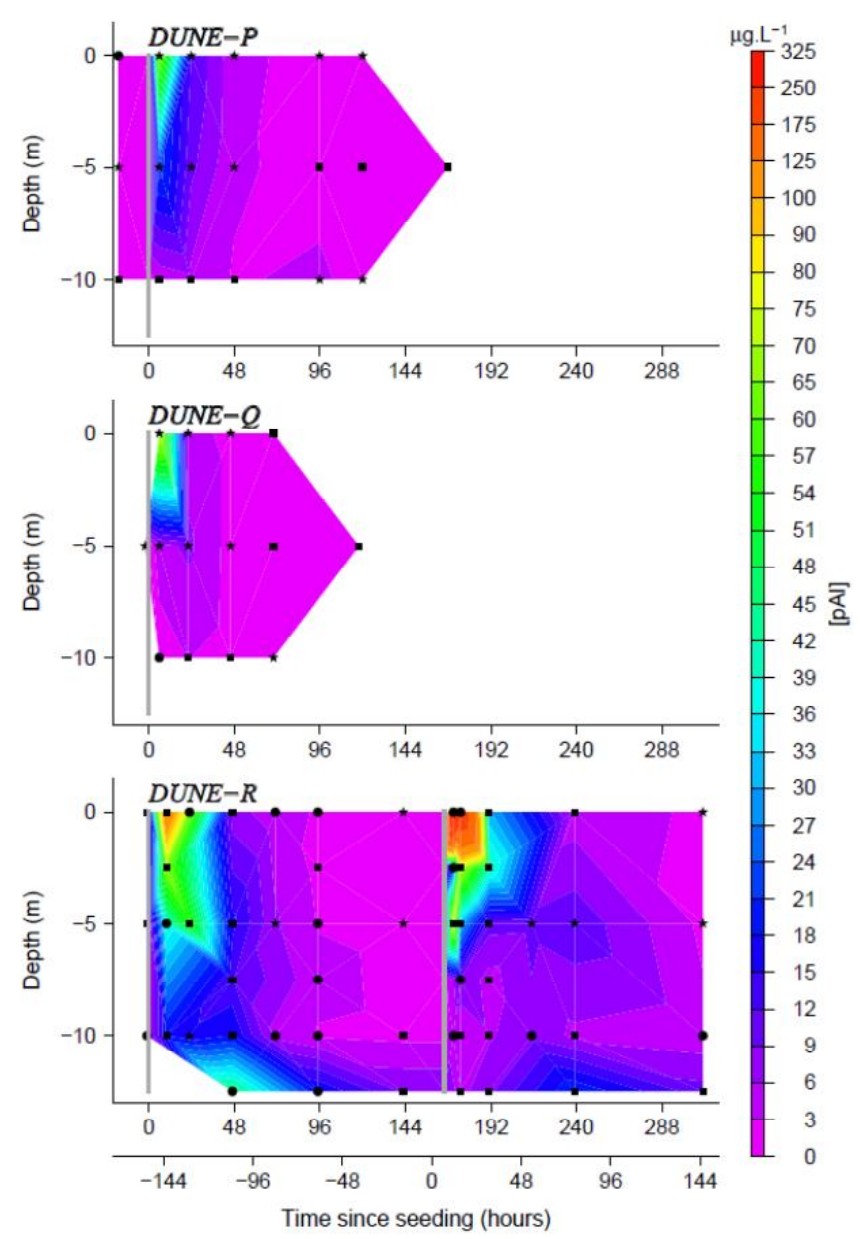

Figure 4. Temporal change of particulate aluminum concentrations in the Dust-Meso for the four seedings. Stars represent the points where the average mesocosms concentration of three replicated mesocosms is used, triangles two replicated mesocosms and circles only one mesocosm. The grey vertical bars highlight the time points when the seeding took place. For experiment $\mathrm{P}$, the pAl are issued from Wagener et al. (2010). containing $\mathrm{Ca}$ in NEC-Dust07. So, for DUNE-Q, we used the $\mathrm{Ca}$ content in sediment traps material to estimate the dissolved part, considering that all the depletion of $\mathrm{Ca}$ is associated with the dissolution of calcium carbonate (Table 5). These estimations also show that in DUNE-Q, only $70 \%$ of the total mass collected in the traps was dust, whereas for the other experiments it accounted for more than $93 \%$ (Table 5). The dissolution of dust constituted a mass loss of around $7 \mathrm{~g}$ (i.e., around $17 \%$ of initial dust mass) in each experiment (Table 6). That implies that only about $34 \mathrm{~g}$ from the $41.5 \mathrm{~g}$ actually seeded remained under particulate form in the mesocosms.

A large part of the introduced dust was not recovered in the sediments traps even after taking account of the dissolution (Fig. 5). We further used the estimated mass percentage of $\mathrm{Al}$ in the sediments traps from the Fig. 3 (top) in order to also consider the dissolution of dust particles during their settling. Doing this, 7 days after seeding, only 52, 11, 57 and $41 \%$ by mass of the lithogenic particles initially added were recovered in the sediment traps in DUNE-P, -Q, -R1 and R2, respectively (Fig. 5). For the DUNE-P and DUNE-R, the temporal change of dust settling was very homogeneous up to $72 \mathrm{~h}$. After $72 \mathrm{~h}$, the settling of dust particles in DUNER2 was significantly lower in comparison to the DUNE-P and DUNE-R1. The low recovery of dust mass in the sediment traps even 7 days after seeding suggests that more than $45 \%$ of dust particles (Fig. 5) had sinking velocities below $2.1 \mathrm{~m} \mathrm{~d}^{-1}$, whereas the recovery after one day indicates that less than $15 \%$ of dust presented sinking velocities higher than $14.7 \mathrm{~m} \mathrm{~d}^{-1}$ for DUNE-P and DUNE-R. This is consistent with the results from Bressac et al. (2012) showing that the higher settling velocity of Saharan dust particles could reach 24 to $87 \mathrm{~m} \mathrm{~d}^{-1}$ during DUNE-R. For DUNE-Q, $89 \%$ of particles had sinking velocities below $2.1 \mathrm{~m} \mathrm{~d}^{-1}$, and $1 \%$ of particles had sinking velocities higher than $14.7 \mathrm{~m} \mathrm{~d}^{-1}$ (Fig. 5). This means that the large majority of deposited dust remained in the water surface layer even 7 days after the seeding. 
Table 6. Mass budget (mg) in mesocosms after the last sampling of pAl in the water column, i.e., 120, 73, 144 and $142 \mathrm{~h}$ for DUNE-P, -Q, $-\mathrm{R} 1$ and $-\mathrm{R} 2$, respectively. The values of dust mass in traps are estimated from Al without correction related to the dissolution. For experiment $\mathrm{P}$, the pAl are issued from Wagener et al. (2010).

\begin{tabular}{lrrrrr}
\hline Experiments & $\begin{array}{r}\text { Dissolved } \\
\text { dust mass }\end{array}$ & $\begin{array}{r}\text { Dust mass in } \\
\text { suspension }\end{array}$ & $\begin{array}{r}\text { Dust mass } \\
\text { in traps }\end{array}$ & $\begin{array}{r}\text { Total dust mass } \\
\text { in mesocosms }\end{array}$ & $\begin{array}{r}\% \\
\text { recovery }\end{array}$ \\
\hline $\mathrm{P}$ & 6412 & 12766 & 20540 & 39718 & $96 \%$ \\
$\mathrm{Q}$ & 8064 & 1147 & 1173 & 10384 & $25 \%$ \\
$\mathrm{R} 1$ & 7322 & 10747 & 22968 & 41038 & $99 \%$ \\
$\mathrm{R} 2$ & 7212 & 12865 & 14063 & 34141 & $82 \%$ \\
\hline
\end{tabular}

Using pAl concentrations in the water column, the remaining mass of dust still in suspension in the mesocosm were estimated to be $12.8,1.1,10.8$ and $12.9 \mathrm{~g}$, respectively, for DUNE-P after 5 days, DUNE-Q after 3 days, DUNE-R1 and DUNE-R2 after 6 days (these times corresponding to the last sampling in the water column) (Table 6). When correcting these numbers by the mass fraction that dissolved from dust, the recoveries were $96,25,99$ and $82 \%$ of the initial dust mass (Table 6). This mass budget shows that a half of dust was found in the sediment traps for DUNE-Q and DUNE-R2 and two-thirds for DUNE-P and DUNE-R1. A critical point of uncertainties in this calculation is the integration of $\mathrm{pAl}$ within the water column to estimate the mass of dust in suspension. As previously noted, no measurement of pAl was available below $10 \mathrm{~m}$ for DUNE-P and DUNE-Q and a potential high concentration of pAl could have been missed, underestimating the final estimated mass of dust. Thus, it is probable that this low depth resolution was insufficient for the case of the $\mathrm{Q}$ experiment, which presented the largest mass fraction in suspension at the end of the experiment. In consequence, this could explain, at least in part, the low rate of recovery for this experiment. Although the low depth resolution could increase the uncertainty on the estimated mass, it is important to note here that the lowest recovery was obtained for DUNE-Q experiment mimicking a dry deposition (see discussion Sect. 4.2).

\subsection{Estimation of fluxes associated with dust deposition}

Settling particles consist of four major components: biogenic opal (opal), biogenic carbonate $\left(\mathrm{bCaCO}_{3}\right)$, lithogenic particles, and organic matter (POC). In the Dust-Meso, the lithogenic particles corresponded essentially to added dust. In consequence, the fraction of dust was calculated from the estimated mass $\%$ of $\mathrm{Al}$ in the sediments traps from the Fig. 3, as for the mass budget. The fraction corresponding to biogenic opal was determined from the measurement of biogenic $\mathrm{Si}$, obtained from sequential leaching following Mosseri et al. (2005). In comparison to open ocean sediment traps studies, we have seen that a large part of $\mathrm{Ca}$ measured in the traps was from added dust and the total mass of $\mathrm{Ca}$ is the sum of $\mathrm{Ca}$ as $\mathrm{Ca}\left(\mathrm{NO}_{3}\right)_{2}, \mathrm{CaCO}_{3}$ and $\mathrm{CaSO}_{4}$ present in dust, plus the $\mathrm{bCaCO}_{3}$. Sulfur concentrations in the traps

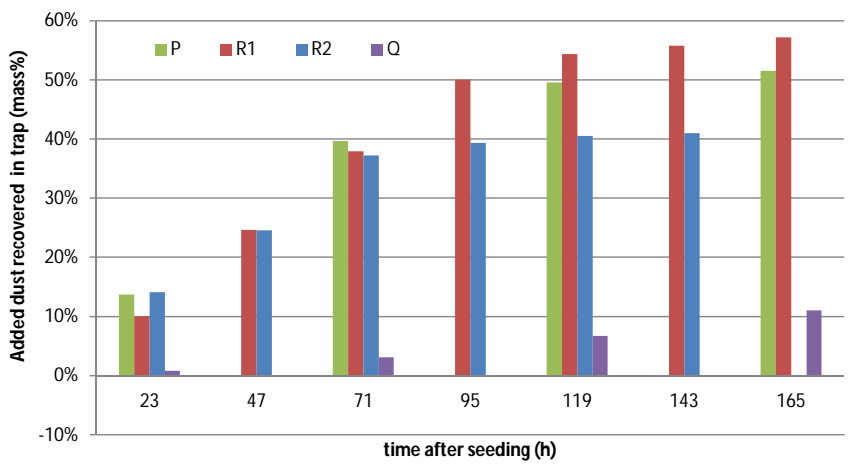

Figure 5. Mass percentage of recovered dust in the sediment traps in comparison to the added mass at $t_{0}$ considering the loss of mass by dissolution of evaporite minerals for the experiments P, R1 and $\mathrm{R} 2$ and by dissolution of calcite for the experiment $\mathrm{Q}$ as a function of time after seeding.

indicate that all the produced gypsum by dust treatment was not completely dissolved. The undissolved mass of $\mathrm{CaSO}_{4}$ was estimated from the mass of particulate $\mathrm{S}$. The total carbonate mass was assessed from the total mass of $\mathrm{Ca}$ minus the mass of $\mathrm{Ca}$ related to gypsum. The biogenic carbonate was finally estimated from the total carbonate mass minus the estimated $\mathrm{CaCO}_{3}$ issued from dust (estimated from the $\mathrm{Ca}$ to total mass scatter plot as for $\mathrm{Al}$ in Fig. 3). The organic matter was estimated as 2.4 times the organic carbon (Klaas and Archer, 2002), which was issued from the total carbon mass less the total carbonate fraction of carbon.

The masses in the Control-Meso were typically at least one order of magnitude lower than the masses obtained in the Dust-Meso. The exported material in Control-Meso was dominated by the POC fraction (30-50\%), and by the lithogenic fraction $(20-30 \%)$ regardless of the experiment. Inversely, the lithogenic fraction was the main component of the mass in the Dust-Meso, representing between 66 to $96 \%$ of the total mass, the lowest percentages being measured 6 days after seeding (not shown). POC represented up to $14 \%$ of the total mass. The highest POC contribution was obtained for DUNE-P and the lowest for DUNE-Q. The total mass, $\mathrm{POC}$, dust, opal and $\mathrm{bCaCO}_{3}$ fluxes have been estimated from the calculated mass fraction in the collected material 
Table 7. Integrated POC, lithogenic, opal and biogenic $\mathrm{CaCO}_{3}$ mass fluxes $\left(\mathrm{mg} \mathrm{m}^{-2} \mathrm{~d}^{-1}\right)$ determined from mass in sediment traps for the four seeding experiments.

\begin{tabular}{llcccc}
\hline & & $\mathrm{P}$ & $\mathrm{Q}$ & $\mathrm{R} 1$ & $\mathrm{R} 2$ \\
\hline \multirow{3}{*}{ POC flux } & control & $4.3 \pm 3.2$ & $2.8 \pm 1.3$ & $6.8 \pm 4.3$ & $1.6 \pm 1.2$ \\
& dust & $21.9 \pm 11.8$ & $5.0 \pm 2.5$ & $17.1 \pm 10.0$ & $10.9 \pm 9.7$ \\
& ratio & $\mathbf{5 . 1}$ & $\mathbf{1 . 8}$ & $\mathbf{2 . 5}$ & $\mathbf{6 . 8}$ \\
\hline \multirow{3}{*}{ Lithogenic flux } & control & $6.3 \pm 7.0$ & $4.4 \pm 2.5$ & $8.0 \pm 6.4$ & $2.5 \pm 2.4$ \\
& dust & $646 \pm 499$ & $63.7 \pm 21.9$ & $565 \pm 392$ & $359 \pm 341$ \\
& ratio & $\mathbf{1 0 3}$ & $\mathbf{1 4}$ & $\mathbf{7 1}$ & $\mathbf{1 4 4}$ \\
\hline \multirow{3}{*}{ Opal flux } & control & $1.5 \pm 1.4$ & $1.0 \pm 0.7$ & $13 \pm 13$ & $1.4 \pm 0.4$ \\
& dust & $30 \pm 24$ & $2.4 \pm 0.7$ & $12 \pm 22$ & $19 \pm 65$ \\
& ratio & $\mathbf{1 9}$ & $\mathbf{2}$ & $\mathbf{1}$ & $\mathbf{1 4}$ \\
\hline \multirow{2}{*}{ CaCO 3 bio flux } & control & $<\mathrm{DL}$ & $0.2 \pm 0.1$ & $1.0 \pm 2.5$ & $1.46 \pm 1.1$ \\
& dust & $28 \pm 29$ & $6.7 \pm 2.5$ & $98.1 \pm 74$ & $61 \pm 56$ \\
& ratio & & $\mathbf{3 4}$ & $\mathbf{9 4}$ & $\mathbf{4 2}$ \\
\hline \multirow{2}{*}{ Litho / POC } & control & 1.5 & 1.6 & 1.2 & 1.6 \\
& dust & 29.5 & 12.8 & 33.1 & 32.9 \\
\hline
\end{tabular}

(Table 7). All fluxes were significantly lower in the DUNE$\mathrm{Q}$ compared to the other experiments, in agreement with the low dust recovery found in the sediment traps of this seeding.

\section{Discussion}

\subsection{Elemental composition of sediment records: a good proxy for atmospheric inputs?}

Chemical elements (except $\mathrm{N}$ ) and total mass are well correlated in the material collected in sediment traps. Such linearity means that the process likely involved in a modification of dust composition (such as dissolution, adsorption, precipitation, aggregation) occurred in the water column before $t=24 \mathrm{~h}$ after the seeding. This confirms that the study of these processes demands a high temporal resolution of dissolved concentrations monitoring as observed by Wuttig et al. (2013). This is in particular the case of evaporite minerals dissolution, releasing $\mathrm{Ca}, \mathrm{S}$ and $\mathrm{N}$. According to our data, the mass content of those elements is altered after dust deposition. Such dissolution implies also a decrease of dust mass during settling (Table 5), modifying the mass percentage of elements in the collected material in the sediment traps (e.g., $\mathrm{Al}$ in Fig. 3). In such very controlled conditions, we observed that the estimation of dust mass from $\mathrm{Al}$ is on average $30 \%$ larger than the actual added mass of dust. As mentioned before, $\mathrm{Al}$ is often used for estimating the dust mass in sediment traps (e.g., Bory et al., 2002). Our results show that the dissolution of evaporite minerals formed during atmospheric dust transport due to cloud processing could generate an overestimation of the dust total mass estimated in this way. The typical comparison between atmospheric and marine dust fluxes estimated from $\mathrm{Al}$ contents shows that estimated atmospheric deposition fluxes are 2-3 times lower than oceanic sediment trap fluxes (Bory et al., 2002; Ternon et al., 2010). This suggests that the uncertainties on the estimation of lithogenic fluxes from $\mathrm{Al}$ content in sediment traps could be explained in part by this discrepancy, at least in areas where dust ageing is observed.

Practically, the interelemental ratios found in sediments are usually used as proxies of terrigenous input $(\mathrm{Ti} / \mathrm{Al}$, $\mathrm{Fe} / \mathrm{Ca}$ and $\mathrm{Ti} / \mathrm{Ca}$ ) (Mahiques et al., 2009; Govin et al., 2012), and of productivity (Ba / Al and Ba / Ti) (Paytan and Kastner, 1996 and Mahiques et al., 2009). Recent studies have shown that the potential of elemental ratios including $\mathrm{Ca}$ as $\mathrm{Fe} / \mathrm{Ca}$ or $\mathrm{Ti} / \mathrm{Ca}$ are too sensitive to dilution effects by biological components to allow reliable imprints of terrigeneous inputs (Govin et al., 2012). Our data support this conclusion by showing that the high dissolution of $\mathrm{Ca}$ in dust triggers an increase in the $\mathrm{Fe} / \mathrm{Ca}$ and $\mathrm{Ti} / \mathrm{Ca}$ ratios in particles, making it difficult to use of these ratios to estimate accurate lithogenic fluxes. On the contrary, our results show the stability of content of $\mathrm{Al}, \mathrm{Fe}$ and $\mathrm{Ti}$ in dust during their sinking in the water column, confirming the reliable use of their interelemental ratios as dust proxies. $\mathrm{Ba}$ in excess, i.e., the fraction of total Ba not associated with the lithogenic material, i.e., marine barite, is used to estimate the $\mathrm{C}$ export flux (e.g., Paytan and Kastner, 1996). During DUNE, the ratio $\mathrm{Ba} / \mathrm{Al}$ was stable in material collected in the sediment traps, meaning that the $\mathrm{Ba}$ in the sediment traps corresponds mainly to the $\mathrm{Ba}$ from dust. Indeed, the biological origin of this element was masked by the high dust mass found in the sediment traps, preventing the calculation of $\mathrm{Ba}$ in excess. In consequence, the use of the $\mathrm{Ba} / \mathrm{Al}$ or $\mathrm{Ba} / \mathrm{Ti}$ ratio as productivity proxies is likely not recommended in case of large dust events such as the one simulated during DUNE. On the 
contrary, the systematic enrichment observed for Co whatever the experiment (Table 4), confirms a supplementary biological source of this element. For example, Co is known to substitute $\mathrm{Zn}$ in the enzyme carbonic anhydrase in some phytoplankton species (e.g Sunda and Huntsman, 1995). An increase of chlorophyll concentrations was observed after dust seeding for DUNE-P and DUNE-R, but not during DUNE$\mathrm{Q}$ (although a strong increase of $\mathrm{N}_{2}$ fixation by diazotrophs was observed, Ridame et al., 2014). Co / Al was consistent with these results since it was higher when the autotrophs response was higher and inversely. We propose that the ratio $\mathrm{Co} / \mathrm{Al}$ could be a good productivity proxy even in the case of large dust inputs. However, it should be tested in "real" (deeper) sediment traps material records.

\subsection{Link between dust deposition state and POC fluxes}

The total and lithogenic fluxes obtained for DUNE-P and DUNE-R (Table 6) were higher than typical fluxes observed in regions under dust deposition influence, typically around $50 \mathrm{mg} \mathrm{m}^{-2} \mathrm{~d}^{-1}$ (Bory et al., 2002 for northeastern tropical Atlantic Ocean; Ternon et al., 2010 for western Mediterranean). However, our data are consistent with the report by Ternon et al. (2010) of high lithogenic marine sediment fluxes at $200 \mathrm{~m}$ depth reaching $\sim 1 \mathrm{~g} \mathrm{~m}^{-2} \mathrm{~d}^{-1}$ as observed after a particularly high dust deposition event of $\sim 22 \mathrm{~g} \mathrm{~m}^{-2}$.

Bressac et al. (2014) showed a high degree of covariance between POC and lithogenic fluxes in the Dust-Meso for DUNE-R. They explained this link through the ballast effect of added dust on the organic matter present in the mesocosms. This conclusion was supported by the optical measurements during DUNE-R showing that the high sinking velocities of Saharan dust pool ( 24 to $87 \mathrm{~m} \mathrm{~d}^{-1}$ ) correspond to the formation of organic-mineral aggregates within the upper few meters of the water column after seeding (Bressac et al., 2012). We observed that the positive covariance between lithogenic and POC fluxes existed also for DUNE-P and DUNE-Q (not shown), indicating a link between dust and POC export in all the experiments. However, our results show that the pattern of sinking of particles was not equivalent for all the experiments (see Sect. 3.3 and Fig. 5). A much slower settling was observed for DUNE-Q, simulating dry deposition of dust. The highest settling was observed for DUNE-P and DUNE-R1 simulating wet deposition of dust.

In order to explain the difference of dust settling in relation with POC, we estimated the mass ratios of lithogenic matter (i.e., dust in the Dust-Meso) to organic carbon in the sediments traps (Litho / POC in Table 7), i.e., dust fluxes normalized to the POC fluxes in the collected material. For all the experiments simulating wet deposition, the mean ratios obtained were very consistent and around 30 . This value is in the range of values found in the case of "real" wet dust deposition events onto surface seawater with high organic matter concentrations (Ternon et al., 2010). The lowest ratio (13) is obtained for DUNE-Q corresponding to a dry deposition.
This value is consistent with the ratio observed by Ternon et al. (2010) in Mediterranean summer conditions with a strong stratification of the water column and low Chl $a$ concentrations. To explain these different ratios, it is important to consider the difference of seeding protocols simulating wet or dry deposition (Table 1), but also the physical and biogeochemical conditions in the four experiments (Guieu et al., 2010, 2014a). During experiment P, stratification of the column water inside the mesocosms was not marked whereas stratification was observed during the whole DUNE-Q experiment and toward the ends of both R-seeding periods. However, the dust settling pattern was quasi-similar for DUNE-P and DUNE-R1, meaning that the stratification effect is probably low. Moreover, initial biogeochemical conditions were typical of oligotrophic conditions for all the experiments with very low Chl $a$ concentrations in the range $0.07-0.11 \mu \mathrm{g} \mathrm{L}-1$ (Ridame et al., 2014). The chlorophyll concentration was at least doubled for DUNE-P and DUNE-R, proving a fertilizing effect of dust on phytoplankton (Ridame et al., 2014). Inversely, no Chl $a$ increase was observed after seeding in the Q experiment. Our results show that the highest POC and lithogenic fluxes were observed when an increase of chlorophyll concentrations was observed. On the contrary, the observations for DUNE-Q simulating dry dust deposition showed a slower dust settling and a low POC export related to an ineffective fertilizing effect for autotroph community. In the case of two successive wet deposition simulations (DUNE-R1 and R2), dust export was less efficient in the second seeding even if the chlorophyll increase was equivalent. However, the initial Chl $a$ concentrations were higher for the second seeding, meaning that fresh organic matter produced after the first seeding had not totally disappeared. This observed primary-productivity dependence of lithogenic fluxes in our controlled oligotrophic conditions shows that a high dust export after a dust deposition event needs both a fertilizing effect to produce new organic matter and mineral ballast. This conclusion supports the work from Ternon et al. (2010) that suggested that the high lithogenic fluxes associated with dust deposition likely occur only when there is simultaneous presence of organic matter and lithogenic material (Ternon et al., 2010). This organic matter could be freshly produced due to a fertilizing effect of deposited dust or older organic matter. The high covariance observed between lithogenic and POC fluxes is similar for all the experiments simulating wet deposition, suggesting that the measured ratio Lithogenic / POC fluxes around 30 (Table 7) could be used as reference to estimate the POC export triggered by a wet dust deposition event.

Recently, Bressac and Guieu (2013) defined the "lithogenic carbon pump" to describe the relation between the lithogenic ballasting and POC export, independently of the biological contribution to POC export stimulated by the dust deposition. They suggested that the age and quantity of organic matter could be also essential to estimate the efficiency of the "lithogenic carbon pump". From this concept, 
Bressac et al. (2014) calculated that this lithogenic carbon pump represented $50 \pm 8$ and $42 \pm 3 \%$ of the total POC fluxes during DUNE-R1 and DUNE-R2, respectively. They propose that the relative decrease in the lithogenic ballasting after the second seeding was due to the scavenging of large quantity of organic matter from the water column following the first seeding. Comparing these conclusions with our observations on the POC fluxes during DUNE-P and DUNE-Q suggests that the "lithogenic carbon pump" was inefficient for DUNE-Q since the POC fluxes in the Dust-Meso were similar with the ones in the Control-Meso. This implies that the initial organic matter probably presented an insufficient concentration or an inappropriate quality (e.g., thickness) to induce lithogenic ballasting in this experiment. However, it is difficult to estimate what was the effect of strong stratification during this experiment on the low POC fluxes. On the contrary, the induced new production during DUNE-P and DUNE-R provided sufficient fresh organic matter to activate the lithogenic carbon pump, while the water column was not strongly stratified. Our results suggest that the "lithogenic carbon pump" mechanism after a dust deposition is more efficient when new production (and thus production of fresh DOM) is induced by the deposition and the stratification is not too marked.

\section{Conclusions}

Elemental particulate composition in the water column and sediment traps constitutes useful data for assessing the fate of mineral dust particles deposited at the ocean surface. From controlled artificial seeding experiments in large mesocosms, we have shown that the dust predominated the particulate phase exported at the base of mesocosms ( $15 \mathrm{~m}$ depth) and that dust particles were still in suspension in the enclosed seawater body $\left(52 \mathrm{~m}^{3}\right) 164 \mathrm{~h}$ after the seeding. Lithogenic and POC fluxes were consistent with direct measured fluxes in sediment traps at $200 \mathrm{~m}$ depth in the water column following a strong desert dust deposition event (NW Mediterranean Sea; Ternon et al., 2010). This confirms that data obtained from our experimental mesocosm approach captured the mechanisms of export following a natural dust deposition event.

About $15 \%$ of the initial dust mass introduced was dissolved in the water column in the first $24 \mathrm{~h}$ after seeding. This loss was due to the rapid dissolution of calcite for DUNE$\mathrm{Q}$ and from the new minerals, as gypsum or calcium nitrate formed by artificial cloud processing of seeded dust in DUNE-P and DUNE-R. In spite of these dissolutions, the interelemental ratio $\mathrm{Ti} / \mathrm{Al}$ of seeded dust remained constant during the dust settling, confirming that this ratio is a good proxy for marine lithogenic fluxes. We showed that relatively high $\mathrm{Ba}$ content in dust prevents the use of $\mathrm{Ba} / \mathrm{Al}$ as productivity proxy in the case of high dust deposition such as the ones mimicked during DUNE. Instead, we identified that the ratio Co / Al was linked to the marine productivity and could be a good candidate as a productivity proxy.

The mass budget in the sediment traps and in the mesocosm revealed differences in the dust settling between the different seeding experiments. The higher mass recoveries were measured in DUNE-P and DUNE-R (Fig. 5) and were associated with the highest POC fluxes. This corresponded to the seeding experiments carried out with EC-Dust, i.e., "aged" dust and simulating wet deposition, when a significant Chl $a$ increase after seeding was observed and the stratification was not marked. Inversely, the experiment Q, simulating a dry deposition event of NEC-Dust, i.e., "fresh" dust, presented the lowest recovery of dust mass in the sediment traps, with around $89 \%$ of dust remaining in the water column after 6 days (Fig. 5). This low dust recovery in the sediment trap was concomitant with (1) a low Chl $a$ increase during this experiment, (2) a low POC export and (3) and a strong stratification. We hypothesize that because dry deposition of fresh dust was inefficient to strongly fertilize autotrophs communities in the mesocosms, the dry deposition of fresh dust in our oligotrophic and stratified conditions was inefficient to induce the necessary dissolved organic matter to trigger high POC fluxes by a ballast effect. On the contrary, wet deposition of aged dust was very efficient to trigger high POC fluxes following new production induced by the new nutrients from the dust. The lithogenic fluxes in this case were typically 30 -fold higher than the POC fluxes. The different dust deposition simulated during DUNE highlighted a series of processes that modulate the export of lithogenic material and POC after a dust deposition. These processes include the fertilizing effect of dust on the autotroph community, the ballast effect between lithogenic particles and dissolved organic matter and the intensity of the stratification. Further studies should focus on the link between the intensity of the POC export and the type of deposition (dry or wet) since our data do not enable us to conclude if this is a critical parameter.

\section{The Supplement related to this article is available online at doi:10.5194/bg-11-5581-2014-supplement.}

Acknowledgements. The authors thank the useful comments of reviewers. The DUNE project, a DUst experiment in a low Nutrient, low chlorophyll Ecosystem, is a fundamental research project funded by the ANR. The sediment trap treatments have been performed by the national service "La Cellule Pièges" from INSU LEFE-CYBER (L. Coppola, N. Leblond). The soil dust samples have been obtained from F. Dulac in collaboration with M. Labiadh from the Tunisian Institute of Arid regions (IRA) in Medenine. T. Wagener was partially supported by a Marie Curie IEF (grant agreement no. PIEF-GA-2009-236694, DAPOP). DUNE was endorsed by the international SOLAS (Surface Ocean-Lower Atmosphere Study) program in February 2009, 
(http://solas-int.org/activities/project-endorsement.html). We thank CNRS-INSU and the Laboratoire d'Océanographie de Villefranche (LOV) for financing this publication.

Edited by: F. Dulac

\section{References}

Averyt, K. B. and Paytan, A.: A comparison of multiple proxies for export production in the equatorial Pacific, Paleoceanog., 19, PA4003, doi:10.1029/2004pa001005, 2004.

Bergametti, G., Gomes, L., Remoudaki, E., Desbois, M., Martin, D., and Buat-Ménard, P.: Present transport and deposition patterns of African dusts to the north-western Mediterranean, in: Paleoclimatology and Paleometeorology: Modern and Past Patterns of Global Atmospheric Transport, edited by: M. Leinen and M. Sarnthein, Kluwer Academic Publishers, 227-251, 1989.

Bonnet, S. and Guieu, C.: Atmospheric forcing on the annual iron cycle in the western Mediterranean Sea: A 1-year survey, J. Geophys. Res., 111, C09010, doi:10.1029/2005JC003213, 2006.

Bory, A., Dulac, F., Moulin, C., Chiapello, I., Newton, P. P., Guelle, W., Lambert, C. E., and Bergametti, G.: Atmospheric and oceanic dust fluxes in the northeastern tropical Atlantic Ocean: How close a coupling?, Ann. Geophys., 20, 2067-2076, 2002,

http://www.ann-geophys.net/20/2067/2002/.

Bressac, M. and Guieu, C.: Post-depositional processes: What really happens to new atmospheric iron in the ocean's surface?, Global Biogeochem. Cy., 27, 859-870, 2013.

Bressac, M., Guieu, C., Doxaran, D., Bourrin, F., Obolensky, G., and Grisoni, J. M.: A mesocosm experiment coupled with optical measurements to assess the fate and sinking of atmospheric particles in clear oligotrophic waters, Geochem. Mar. Lett., 32, 153-164, 2012.

Bressac, M., Guieu, C., Doxaran, D., Bourrin, F., Desboeufs, K., Leblond, N., and Ridame, C.: Quantification of the lithogenic carbon pump following a simulated dust-deposition event in large mesocosms, Biogeosciences, 11, 1007-1020, doi:10.5194/bg-11-1007-2014, 2014.

Buseck, P. R. and Posfai, M. 1.: Airborne minerals and related aerosol particles: Effects on climate and the environment, Proc. Nat. Acad. Sci., 96, 3372-3379, 1999.

Desboeufs, K., Losno, R., Vimeux, F., and Cholbi, S.: pH dependent dissolution of wind transported Saharan dust, J. Geophys. Res., 104, 21287-21299, 1999.

Desboeufs, K. V., Losno, R., and Colin, J. L.: Factors influencing aerosol solubility during cloud processes, Atmos. Environ., 35, 3529-3537, 2001.

Fischer, G., Karakas, G., Blaas, M., Ratmeyer, V., Nowald, N., Schlitzer, R., Helmke, P., Davenport, R., Donner, B., Neuer, S., and Wefer, G.: Mineral ballast and particle settling rates in the coastal upwelling system off NW Africa and the South Atlantic, Int. J. Earth Sci., 98, 281-298, 2009.

Frigola, J., Moreno, A., Cacho, I., Canals, M., Sierro, F. J., Flores, J. A., Grimalt, J. O., Hodell, D. A., and Curtis, J. H.: Holocene climate variability in the western Mediterranean region from a deepwater sediment record, Paleoceanogr., 22, PA2209, doi:10.1029/2006pa001307, 2007.

Goutx, M., Momzikoff, M., Striby, L., Andersen, V., Marty, J.-C., and Vescovali, I.: High-frequency fluxes of labile compounds in the central Ligurian Sea, northwestern Mediterranean, Deep-Sea Res. I, 47, 533-556, 2000.

Govin, A., Holzwarth, U., Heslop, D., Ford Keeling, L., Zabel, M., Mulitza, S., Collins, J. A., and Chiessi, C. M.: Distribution of major elements in Atlantic surface sediments $\left(36^{\circ} \mathrm{N} ; 49^{\circ} \mathrm{S}\right)$ : Imprint of terrigenous input and continental weathering, Geochem. Geophys. Geosyst., 13, Q01013, doi:10.1029/2011gc003785, 2012.

Guerzoni, S., Chester, R., Dulac, F., Herut, B., Loye-Pilot, M.-D., Measures, C., Migon, C., Molinaroli, E., Moulin, C., and Rossini, P.: The role of atmospheric deposition in the biogeochemistry of the Mediterranean Sea, Progr. Oceanogr., 44, 147-190, 1999.

Guieu, C., Dulac, F., Desboeufs, K., Wagener, T., Pulido-Villena, E., Grisoni, J. M., Louis, F., Ridame, C., Blain, S., Brunet, C., Bon Nguyen, E., Tran, S., Labiadh, M., and Dominici, J. M.: Large clean mesocosms and simulated dust deposition: a new methodology to investigate responses of marine oligotrophic ecosystems to atmospheric inputs, Biogeosciences, 7, 27652784, doi:10.5194/bg-7-2765-2010, 2010.

Guieu, C., Dulac, F., Ridame, C., and Pondaven, P.: Introduction to project DUNE, a DUst experiment in a low Nutrient, low chlorophyll Ecosystem, Biogeosci., 11, 425-442, 2014a.

Guieu, C., Ridame, C., Pulido-Villena, E., Bressac, M., Desboeufs, K., and Dulac, F.: Dust deposition in an oligotrophic marine environment: impact on the carbon budget, Biogeosci. Discuss., 11, 1707-1738, doi:10.5194/bgd-11-1707-2014, 2014b.

Heimbürger, A., Tharaud, M., Monna, F., Losno, R., Desboeufs, K., and Nguyen, E. B.: SLRS-5 Elemental Concentrations of ThirtyThree Uncertified Elements Deduced from SLRS-5/SLRS-4 Ratios, Geostand. Geoanal. Res., 37, 77-85, 2013.

Heimbürger, L.-E., Migon, C., Losno, R., Miquel, J.-C., Thibodeau, B., Stabholz, M., Dufour, A., and Leblond, N.: Vertical export flux of metals in the Mediterranean Sea, Deep-Sea Res. I, 87, 14-23, 2014.

Klaas, C. and D. E. Archer, Association of sinking organic matter with various types of mineral ballast in the deep sea: Implications for the rain ratio, Global Biogeochem. Cy., 16, 1116, doi:10.1029/2001GB001765, 2002.

Krom, M. D., Herut, B., and Mantoura, R. F. C.: Nutrient budget for the eastern Mediterranean: Implications for P limitation, Limnol. Oceanogr., 49, 1582-1592, 2004.

Lee, C., Peterson, M. L., Wakeham, S. G., Armstrong, R. A., Cochran, J. K., Miquel, J. C., Fowler, S. W., Hirschberg, D., Beck, A., and Xue, J.: Particulate organic matter and ballast fluxes measured using time-series and settling velocity sediment traps in the northwestern Mediterranean Sea, Deep-Sea Res. II, 56, 1420-1436, 2009.

Loÿe-Pilot, M. D., Martin, J. M., and Morelli, J.: Influence of Saharan dust on rain acidity and atmospheric input to the Mediterranean, Nature, 321, 427-428, 1986.

Mahiques, M. M., Wainer, I. E. K. C., Burone, L., Sousa, S. H. M. Silveira, I. C. A., Bícego, M. C., Alves, D. P., and Hammer, O.: A high-resolution Holocene record on the Southern Brazilian shelf: paleoenvironmental implications, Quat. Int., 206, 52-61, 2009.

Moreno, A., Cacho, I., Canals, M., Prins, M. A., Sánchez Goñi, M. F., Grimalt, J. O., and Weltje, G. J.: Saharan Dust Transport and High-Latitude Glacial Climatic Variability: The Alboran Sea Record, Quat. Res., 58, 318-328, 2002.

Mosseri, J., Quéguiner, B., Rimmelin, P., Leblond, N., and Guieu, C.: Silica fluxes in the northeast Atlantic frontal zone of Mode 
Water formation $\left(38-45^{\circ} \mathrm{N}, 16-22^{\circ} \mathrm{W}\right)$ in $2001-2002$, J. Geophys. Res., 110, C07S19, doi:10.1029/2004JC002615, 2005.

Neuer, S., Torres-Padroń, M. E., Gelado-Caballero, M. D., Rueda, M. J., Hernańdez-Brito, J., Davenport, R., and Wefer, G.: Dust deposition pulses to the eastern subtropical North Atlantic gyre: Does ocean's biogeochemistry respond?, Global Biogeochem. Cy., 18, GB4020, doi:10.1029/2004GB002228, 2004.

Paytan, A. and Kastner, M.: Benthic Ba fluxes in the central Equatorial Pacific, implications for the oceanic Ba cycle, Earth Planet. Sci. Lett., 142, 439-450, 1996.

Ploug, H., Iversen, M. H., and Fisher, G.: Ballast Sinking velocity, and apparent diffusivity within marine snow and zooplankton fecal pellets: implications for substrate turnover by attached bacteria. Limnol. Oceanogr., 53, 1878-1886, 2008.

Pulido-Villena, E., Rérolle, V., and Guieu, C.: Transient fertilizing effect of dust in P-deficient LNLC surface ocean, Geophys. Res. Lett., 37, L01603, 10.1029/2009g1041415, 2010.

Ridame, C., Guieu, C., and L'Helguen, S.: Strong stimulation of $\mathrm{N}_{2}$ fixation in oligotrophic Mediterranean Sea: results from dust addition in large in situ mesocosms, Biogeosciences, 10, 73337346, doi:10.5194/bg-10-7333-2013, 2013.

Ridame, C., Dekaezemacker, J., Guieu, C., Bonnet, S., L'Helguen, S., and Malien, F.: Phytoplanktonic response to contrasted Saharan dust deposition events during mesocosm experiments in LNLC environment, Biogeosci. Discuss., 11, 753-796, doi:10.5194/bgd-11-753-2014, 2014.
Sullivan, R. C., Guazzotti, S. A., Sodeman, D. A., and Prather, K. A.: Direct observations of the atmospheric processing of Asian mineral dust, Atmos. Chem. Phys., 7, 1213-1236, doi:10.5194/acp-7-1213-2007, 2007.

Sunda, W., G. and S. A. Huntsman: Cobalt and zinc interreplacement in marine phytoplankton: Biological and geochemical implications, Limnol. Oceanogr., 40, 1404-1417, 1995.

Ternon, E., Guieu, C., Loye-Pilot, M. D., Leblond, N., Bosc, E., Gasser, B., Miquel, J. C., and Martin, J.: The impact of Saharan dust on the particulate export in the water column of the North Western Mediterranean Sea, Biogeosciences, 7, 809-826, 2010, http://www.biogeosciences.net/7/809/2010/.

Wagener, T., Guieu, C., and Leblond, N.: Effects of dust deposition on iron cycle in the surface Mediterranean Sea: results from a mesocosm seeding experiment, Biogeosciences, 7, 3769-3781, doi:10.5194/bg-7-3769-2010, 2010.

Wuttig, K., Wagener, T., Bressac, M., Dammshauser, A., Streu, P., Guieu, C., and Croot, P. L.: Impacts of dust deposition on dissolved trace metal concentrations ( $\mathrm{Mn}, \mathrm{Al}$ and $\mathrm{Fe})$ during a mesocosm experiment, Biogeosciences, 10, 2583-2600, doi:10.5194/bg-10-2583-2013, 2013. 